\title{
$\mathbb{A}$ Economics Bulletin
}

Volume 36, Issue 2

\section{Causal linkages between electricity consumption and GDP in Thailand: evidence from the bounds test}

\author{
Komain Jiranyakul \\ National Institute of Development Administration
}

\begin{abstract}
This paper investigates the causal relationship between electricity consumption and real GDP by applying the bounds testing for cointegration in a multivariate framework. The error correction mechanism is employed to detect causal relationship in the presence of cointegration among three variables. Empirical results for Thailand during 2001Q1 and 2014Q2 suggest that there is long-run unidirectional causality between electricity consumption and real GDP. The source of causation in the long run is found by the significance of the error correction terms in the Wald F-test. In the short run, bidirectional causal relationship between electricity consumption and economic growth is observed. The findings give implications for electricity efficiency and alternative energy sources in the long run.
\end{abstract}

The author is grateful to two anonymous referees for their comments and suggestions.

Citation: Komain Jiranyakul, (2016) "Causal linkages between electricity consumption and GDP in Thailand: evidence from the bounds test", Economics Bulletin, Volume 36, Issue 2, pages A90

Contact: Komain Jiranyakul - komain j@hotmail.com.

Submitted: December 14, 2014. Published: May 18, 2016. 


\section{Introduction}

Previous studies investigate the impact of energy consumption on real GDP using popular cointegration techniques to find a long-run relationship between the two variables. Both short-run and long-run causality have been examined in advanced and developing or emerging market economies. There can be unidirectional or bidirectional causality between energy and GDP. It is also possible that the neutrality hypothesis exists, i.e., energy consumption does not cause GDP or GDP does not cause energy consumption. Earlier study by Kraft and Kraft (1978) shows that energy consumption Granger causes GNP in the United States during 1947 and 1974. However, Yu and Jin (1992), among others, find a long-run causality of energy consumption to output while Glausure and Lee (1997) find bidirectional causality between energy consumption and GDP in South Korea and Singapore. Asafu-Adjaye (2000) estimates the causal relationships between energy consumption and income for India, Indonesia, the Philippines and Thailand. He finds unidirectional causality running from energy consumption to income in India and Indonesia and bidirectional causality in the Philippines and Thailand. Oh and Lee (2004) re-examine the causal relationship between energy consumption and real GDP in Korea over the period 1970-1999 by estimating a vector error correction mechanism to perform the Granger causality test and find a long-run bidirectional causality between energy consumption and GDP.

Many researchers have focused on electricity consumption that can affect real GDP because electricity generation and sales have induced much attention to policy debate. Yoo (2005) investigates both short-run and long-run causality between electricity consumption and economic growth in South Korea over the 1970-2002 period, and finds bidirectional causality between the two variables. Ho and Siu (2007) find unidirectional causality running from electricity consumption to real GDP in Hong Kong. Chen et al. (2007) find that the directions of causality between electricity consumption and real GDP are mixed among ten Asian economies when the data for individual countries are analyzed. However, bidirectional causality is found in the panel data analysis. Narayan and Smyth (2009) use a panel dataset of the Middle Eastern countries to examine the relationship between electricity consumption and GDP and find bidirectional causality between the two variables. Chandran et al. (2010) examine the relationship between electricity consumption and real GDP for Malaysia during 1971 and 2003. They find that electricity consumption, real GDP and price are cointegrated. In addition, there is a unidirectional causality running from electricity consumption to economic growth. Sami (2011) finds that real per capita income causes electricity consumption in Japan. Faisal and Nirmalya (2013) find that electricity consumption does not cause growth in India, but there is bidirectional causality between the two variables in Pakistan. Halkos and Tzeremes (2014) use a sample of 35 countries over the period from 1990-2011 to examine the relationship between electricity consumption from renewable sources and GDP. They find that electricity consumption from renewable sources will not cause higher GDP in emerging and developing countries.

While empirical results pertaining to the electricity consumption-GDP relationship are mixed, including the previous results using Thailand's data, it is interesting to reanalyze both long-run and short-run causality of the two variables for Thailand using recently available quarterly data. The present paper contributes to the literature in that 
it provides evidence that there exist unidirectional long-run causality running from GDP to electricity consumption and bidirectional short-run causality in Thailand, which is an emerging market economy because the country is classified as a developing country with moderate per capita income. Comparisons of the results from this paper with those of previous studies using Thailand's data are worth mentioning. Chen et al. (2007) directly investigate electricity consumption-GDP relationship using annual data from 1971 to 2002 and find no causality for Thailand. The aggregate energy consumption-income relationship investigated by Asafu-Adjaye (2000) using Thailand's annual data from 1973 to 1995 show the existence of bidirectional causality between the two variables. The present paper reexamines the electricity consumption-GDP relationship for Thailand using recently available quarterly data. Specifically, this paper attempts to examine the causal linkages between electricity consumption and real GDP in Thailand by employing the data from 2000Q1 to 2014Q2. The analytical framework for causality tests comprises two stages. In the first stage, the bounds test or autoregressive distributed lag (ARDL) procedure is conducted. In the second stage, the error correction mechanism in the presence of cointegration is used to detect both short-run and long-run causal relationships between electricity consumption and real GDP. The paper is organized as the following. The next section presents the data description and methods of estimation. Section 3 gives empirical results. The final section concludes.

\section{Data and Methodology}

Quarterly data during 2000Q1 and 2014Q2 are used in the analysis. The advantage of using quarterly data is that a larger sample size can be used in the analysis. The data of electricity consumption are obtained from the Electricity Generating Authority of Thailand and the Provincial Electricity Authority, Ministry of Interior. Energy price index series is obtained from the Bureau of trade and economic indices, Ministry of commerce. Real GDP series is obtained from the office of National Economic and Social Development Board. These available data are also tabulated by the Bank of Thailand. Energy consumption is measured in billion kilowatt hours while GDP at 1988 constant prices is measured in billions of baht (domestic currency). All series are transformed to logarithmic series. The number of observations is 58 .

In this study, the bounds testing for cointegration proposed by Pesaran et al. (2001) is adopted. The procedure is used to test for the existence of level relationship between a variable and its regressors when the order of integration of each variable is not certainly known. Even though unit root tests are not required, this procedure is not applicable when any series is integrated of order larger than one (see Oteng-Abayie and Frimpong, 2006). The variables in the model can be either integrated of order zero, I(0), or integrated of order one, I(1), or might be mixed between I(0) and I(1).

The stationarity property of the data is tested using the PP tests by Phillips and Perron (1998) on first differences of the series and the results are shown in Table 1.

Table 1 Results of unit root tests

\begin{tabular}{lll}
\hline Variable & PP test (constant) & $\begin{array}{l}\text { PP test (constant and a } \\
\text { linear trend) }\end{array}$ \\
\hline$\Delta e c$ & $-10.730[13]$ & $-10.705[13]$
\end{tabular}




\begin{tabular}{lll} 
& & \\
\cline { 2 - 3 }$\Delta p$ & $(0.000)^{* * *}$ & $(0.001)^{* * *}$ \\
& $-14.608[55]$ & $-15.891[55]$ \\
$\Delta y$ & $(0.000)^{* * *}$ & $(0.001)^{* * *}$ \\
& $-13.607[16]$ & $-17.330[15]$ \\
& $(0.000)^{* * *}$ & $(0.001)^{* * *}$
\end{tabular}

Note: $\Delta$ denotes first difference operator. The variables: $e c$ is electricity consumption, $p$ is energy price index, and $y$ is real GDP. The number in bracket is optimal bandwidth determined by Bartlett kernel. The number in parenthesis is the probability of accepting the null hypothesis of unit root. $* * *$ indicates significance at the 1 percent level.

The results in Table 1 ensure that the maximum order of integration of the three variables is one because the null hypothesis of unit root is rejected. Therefore, the bounds test is applicable to the data. This bounds test can provide unbiased long-run estimates and valid test statistics. The long-run equilibrium relationship between electricity consumption, energy price index and real GDP can be express as:

$$
\begin{gathered}
e c_{t}=a_{10}+b_{11} p_{t}+c_{12} y_{t}+e_{1 t} \\
p_{t}=a_{20}+b_{21} e c_{t}+c_{22} y_{t}+e_{2 t} \\
y_{t}=a_{30}+b_{31} e c_{t}+c_{32} p_{t}+e_{3 t}
\end{gathered}
$$

where $\Delta$ denotes first difference operator, $e c$ is the log of electricity consumption, $p$ is the log of energy price index, and $y$ is the log of real GDP. The demand side approach or electricity demand function is represented in (1). Because of the unavailability of electricity price series, the energy price index, denoted by $p$, is used as a proxy of electricity price. Chandran et al. (2010) and Oh and Lee (2004) use consumer price index as a proxy of electricity price due to the lack of the data of electricity price. To examine the impact of electricity consumption and real GDP on price, (2) is used while (3) is used to examine the impact of electricity consumption and price on real GDP.

The unrestricted error correction models of this ARDL procedure can be expressed as:

$$
\begin{aligned}
& \Delta e c_{t}=a_{10}+\delta_{11} e c_{t-1}+\delta_{12} p_{t-1}+\delta_{13} y_{t-1}+\sum_{i=1}^{p 1} \beta_{1 i} \Delta e c_{t-i}+\sum_{j=0}^{p 2} \gamma_{1 j} \Delta p_{t-j}+\sum_{k=0}^{p 3} \varphi_{1 k} \Delta y_{t-k}+\varepsilon_{1 t} \\
& \Delta p_{t}=a_{20}+\delta_{21} p_{t-1}+\delta_{22} e c_{t-1}+\delta_{23} y_{t-1}+\sum_{i=1}^{q 1} \beta_{2 i} \Delta p_{t-i}+\sum_{j=0}^{q 2} \gamma_{2 j} e c_{t-j}+\sum_{k=0}^{q 3} \varphi_{2 k} \Delta y_{t-k}+\varepsilon_{2 t} \\
& \Delta y_{t}=a_{30}+\delta_{31} y_{t-1}+\delta_{32} e c_{t-1}+\delta_{33} p_{t-1}+\sum_{i=1}^{r 1} \beta_{3 i} \Delta y_{t-i}+\sum_{j=0}^{r 2} \gamma_{3 j} \Delta e c_{t-j}+\sum_{k=0}^{r 3} \varphi_{3 k} \Delta p_{t-k}+\varepsilon_{3 t}
\end{aligned}
$$


There are two steps in the bounds testing for cointegration. The first step is to estimate (4) - (6) using ordinary least squares method to determine the existence of a long-run relationship between the three variables. This is done by conducting an $\mathrm{F}$ test for the joint significance of the coefficients of lagged level variables. The null hypothesis: $H_{0}: \delta_{i 1}=\delta_{i 2}=\delta_{i 3}=0, i=1,2,3$ is tested against the alternative hypothesis: $H_{a}: \delta_{i 1} \neq \delta_{i 2} \neq \delta_{i 3} \neq 0, i=1,2,3$. In other words, the models in equations (4) - (6) are tested against the models without lagged level variables, which are the ARDL models, to obtain the computed F-statistics. If cointegration exists, the computed F-statistic will be larger than the upper bound critical value. If cointegration does not exist, the computed F-statistic will be smaller than the lower bound critical value. The computed F-statistic that takes the value between the upper bound and lower bound critical values will lead to an inconclusive result. The existence of cointegration gives the error correction mechanism (ECM) expressed as:

$$
\begin{aligned}
& \Delta e c_{t}=a_{10}+\lambda_{1} e_{1 t-1}+\sum_{i=1}^{p 1} \beta_{1 i} \Delta e c_{t-i}+\sum_{j=0}^{p 2} \gamma_{1 j} \Delta p_{t-j}+\sum_{k=0}^{p 3} \varphi_{1 k} \Delta y_{t-k}+u_{1 t} \\
& \Delta p_{t}=a_{20}+\lambda_{2} e_{2 t-1}+\sum_{i=1}^{q 1} \beta_{2 i} \Delta p_{t-i}+\sum_{j=0}^{q 2} \gamma_{2 j} \Delta e c_{t-j}+\sum_{k=0}^{q 3} \varphi_{2 k} \Delta y_{t-k}+u_{2 t} \\
& \Delta y_{t}=a_{30}+\lambda_{3} e_{3 t-1}+\sum_{i=1}^{r 1} \beta_{3 i} \Delta y_{t-i}+\sum_{j=0}^{r 2} \gamma_{3 j} \Delta e c_{t-j}+\sum_{k=0}^{r 3} \varphi_{3 k} \Delta p_{t-k}+u_{3 t}
\end{aligned}
$$

where $e_{i t-1}$ is the error correction term (ETC), which is the one-period lag of residuals obtained from the ordinary least squares estimate of level relationship between the three variables in (1)-(3). The coefficient $\lambda_{\mathrm{i}}$ is the speed of adjustment toward the long-run equilibrium. The models in (7) - (9) depict short-run dynamics and show how fast any deviation from the long-run equilibrium will be corrected. If the coefficient of the ETC is significantly negative and takes the absolute value of less than one, any deviation from the long-run equilibrium relationship will be rapidly corrected. The main advantage of the conditional ARDL procedure in testing for cointegration is that re-parameterization of the model into the equivalent vector error correction model is not required compared with other techniques of cointeration tests. The ECM representations show short-run relationship between changes in levels of the three variables and their lags.

In conducting Granger causality test when cointegration among variables exists, one can find at least one direction of causality. However, the bounds test results of shortrun dynamics do not explicitly show the directions of causality between the three variables. Therefore, the vector autoregressive (VAR) model augmented with the ECT can be used in stead (see Granger, 1988). The VAR model can be specified as:

$$
\begin{aligned}
& \Delta e c_{t}=a_{10}+\lambda_{1} e_{1 t-1}+\sum_{i=1}^{p} \beta_{1 i} \Delta e c_{t-i}+\sum_{i=1}^{p} \gamma_{1 i} \Delta p_{t-i}+\sum_{i=1}^{p} \varphi_{1 i} \Delta y_{t-i}+v_{1 t} \\
& \Delta p_{t}=a_{20}+\lambda_{2} e_{2 t-1}+\sum_{i=1}^{p} \beta_{2 i} \Delta p_{t-i}+\sum_{i=1}^{p} \gamma_{2 i} \Delta e c_{t-i}+\sum_{i=1}^{p} \varphi_{2 i} \Delta y_{t-i}+v_{2 t}
\end{aligned}
$$




$$
\Delta y_{t}=a_{30}+\lambda_{3} e_{3 t-1}+\sum_{i=1}^{p} \beta_{3 i} \Delta y_{t-i}+\sum_{i=1}^{p} \gamma_{3 i} \Delta e c_{t-i}+\sum_{i=1}^{p} \varphi_{3 i} \Delta p_{t-i}+v_{3 t}
$$

If cointegration does not exist, the ECTs will be excluded from the augmented VAR model. The short-run causation can be tested by the null hopotheses Ho: $\gamma_{1 \mathrm{i}}=0, \varphi_{1 \mathrm{i}}=0$ in (10), Ho: $\gamma_{2 \mathrm{i}}=0, \varphi_{2 \mathrm{i}}=0$ in equation (11), and $\gamma_{3 \mathrm{i}}=0, \varphi_{3 \mathrm{i}}=0$ in (12). For long-run causality, the null hypotheses are the coefficients of the ECTs are zero. These Wald tests are performed by Ho and Lee (2004), and Narayan and Smyth (2009), among others.

\section{Empirical Results}

Since the variables may be $\mathrm{I}(0)$ or $\mathrm{I}(1)$ series, or are mutually cointegrated, the bounds test is performed to the models specified in the previous section. According to Pesaran and Shin (1999), one can obtain the preferred ECM representation in cointgeration analysis. In case of small sample size in the present study, the preferred ECMs are obtained by choosing suitable parsimonious ARDL models, which include the dummy variable, D0709, to detect the impact of the subprime crisis on level relationships of the three variables. This dummy variable is defined as D0709 is 1 over the period 2007Q4-2009Q2, and zero elsewhere. The results of cointegration test are reported in Table 2.

Table 2 Results of cointegration test

\begin{tabular}{llll}
\hline Order of variable & ARDL model & $\begin{array}{l}\text { Serial correlation } \\
\left(\chi_{(2)}^{2}\right)\end{array}$ & Computed F \\
\hline$(\mathrm{ec}, \mathrm{p}, \mathrm{y})$ & $(2,1,1)$ & $\begin{array}{l}1.308 \\
(\mathrm{p} \text {-value }=0.520)\end{array}$ & 6.79 \\
\hline$(\mathrm{p}, \mathrm{ec}, \mathrm{y})$ & $(2,1,1)$ & $\begin{array}{l}2.481 \\
(\mathrm{p} \text {-value }=0.289)\end{array}$ & 3.20 \\
\hline$(\mathrm{y}, \mathrm{ec}, \mathrm{p})$ & $(2,1,0)$ & $\begin{array}{l}2.903 \\
(\mathrm{p} \text {-value }=0.234)\end{array}$ & 31.66 \\
\hline Critical F & 1 percent & 5 percent & 10 percent \\
\hline Upper bound & 7.84 & 4.85 & 4.14 \\
Lower bound & 6.48 & 3.79 & 3.17 \\
\hline
\end{tabular}

Note: The variables: $e c$ is electricity consumption, $p$ is energy price index, and $y$ is real GDP. $\mathrm{P}$-value is the probability of accepting the null hypothesis of no serial correlation in the residuals. Critical F statistic is obtained from Table CI (iii) Case III in Pesaran et al. (2001).

The results from Table 2 show that the chosen ARDL models are free of serial correlation because the Chi-square statistics show that the null hypothesis of no serial correlation is accepted. When electricity consumption is the dependent variable as specified in (4), the computed F statistic is 6.79, which is greater than the $5 \%$ upper bound critical value of 4.85 , and thus cointegration exists. On the contrary, if energy price is the dependent variable, the computed $\mathrm{F}$ statistic is 3.20 , which is between the upper and lower bound critical values at the $10 \%$ level of significance, and the result is inconclusive. For the model with real GDP as the dependent variable, the computed F-statistic is 31.66 , which is greater than the $1 \%$ upper bound critical value, and thus cointegration exists. It can be concluded that there are two cointegrating equations 
that should be further analyzed. Table 3 reports the results of level relationship and short-run dynamics when electricity consumption is the dependent variable.

Table 3 Results of long-run and short-run dynamics estimates of the impact of price and real GDP on electricity consumption, 2000Q1 to 2014Q2

Panel A. Long-run estimation

with $e c_{\mathrm{t}}$ as dependent variable

\begin{tabular}{ll}
\hline & Coefficient \\
$p_{t}$ & $0.367(4.730)^{* * *}$ \\
$y_{t}$ & $0.542(4.252)^{* * *}$ \\
Constant & $-1.865(3.389)^{* * *}$ \\
Adjusted ${ }^{2}$ & 0.910 \\
\hline Panel B. ECM estimation with $\Delta e c_{\mathrm{t}}$ as & \\
dependent variable & \\
ECT & $-0.349(-2.233)^{* *}$ \\
$\Delta e c_{t-1}$ & $-0.112(-0.744)$ \\
$\Delta e c_{t-2}$ & $-0.596(-4.469)^{* * *}$ \\
$\Delta p_{t}$ & $0.116(1.758)^{*}$ \\
$\Delta p_{t-1}$ & $0.078(1.019)$ \\
$\Delta y_{t}$ & $0.022(0.156)$ \\
$\Delta y_{t-1}$ & $-0.324(-2.991)^{* * *}$ \\
$D 070{ }_{t}$ & $-0.039(-2.666)^{* *}$ \\
$c o n s t a n t$ & $0.025(4.168)^{* * *}$ \\
Adjusted ${ }^{2}$ & 0.653 \\
\hline Diagnostic tests: & \\
Functional form (FF) & $0.146(\mathrm{p}=0.702)$ \\
Serieal correlation (LM) & $4.043(\mathrm{p}=0.133)$ \\
Normality (Jarque Bera) & $0.024(\mathrm{p}=0.433)$ \\
Heteroskedasticity (ARCH) & $0.024(\mathrm{p}=0.054)$ \\
\hline
\end{tabular}

Note: The variables: $e c$ is electricity consumption, $p$ is energy price index, and $y$ is real GDP. The number in parenthesis is t-statistic. $p$ is the probability of accepting the null hypotheses that there is no serial correlation, no heteroskedasticity, and residuals are normally distributed. $* * * * *$ and $*$ denote significance at the 1,5 and 10 percent level, respectively.

In the long run, a one percent increase in real GDP causes an increase in electricity consumption by 0.54 percent (Panel A of Table 3). This indicates that real GDP is one of the main determinants of electricity consumption. Therefore, the estimated equation illustrates the contribution of real GDP to electricity consumption. The impact of price on electricity consumption is significantly positive, which implies that the economy depends on electricity regardless of the increasing trend of energy price. The short-run dynamics result from ECM estimate is illustrated in Panel B of Table 3. In the short run, the relationship between output growth and a change in electricity consumption is positive, but is not statistically significant. Furthermore, only the coefficient of lagged economic growth is statistically significant. Therefore, a change in real GDP does affect the electricity consumption in the short run. The negative impact of the subprime crisis in the short-run is visible. The estimated coefficient of the ECT is significantly negative and takes the absolute value of less than one. This indicates that any deviation from long-run equilibrium will be corrected. 
The other cointegrating equation and short-run dynamics estimates are shown in Table 4.

Table 4 Results of long-run and short-run dynamics estimates of the impact of electricity consumption and price on real GDP, 2000Q1 to 2014Q2

\begin{tabular}{ll}
\hline $\begin{array}{l}\text { Panel A. Long-run estimation } \\
\text { with } y_{\mathrm{t}} \text { as dependent variable }\end{array}$ & \\
\hline & Coefficient \\
$e c_{t}$ & $0.457(4.252)^{* * *}$ \\
$p_{t}$ & $0.296(3.704)^{* * *}$ \\
Constant & $4.011(31.537)^{* * *}$ \\
Adjusted $\mathrm{R}^{2}$ & 0.903 \\
\hline Panel B. ECM estimation & \\
with $\Delta y_{\mathrm{t}}$ as dependent variable & \\
ECT & $-0.827(-6.333)^{* * *}$ \\
$\Delta y_{t-1}$ & $0.055(0.488)$ \\
$\Delta y_{t-2}$ & $-0.235(-2.147)^{* *}$ \\
$\Delta e c_{t}$ & $0.052(0.598)$ \\
$\Delta e c_{t-1}$ & $-0.565(-6.816)^{* * *}$ \\
$\Delta p_{t}$ & $0.094(1.812)^{*}$ \\
$D 0709_{t}$ & $-0.012(-1.062)$ \\
$c o n s t a n t$ & $0.017(3.727)^{* * *}$ \\
Adjusted R & \\
\hline Diagnostic tests: & 0.709 \\
Functional form (FF) & \\
Serieal correlation (LM) & $3.083(\mathrm{p}=0.079)$ \\
Normality (Jarque Bera) & $3.334(\mathrm{p}=0.189)$ \\
Heteroskedasticity (ARCH) & $3.775(\mathrm{p}=0.151)$ \\
\hline Note: The variab: $e c$ is & $0.120(\mathrm{p}=0.729)$ \\
\hline
\end{tabular}

Note: The variables: $e c$ is electricity consumption, $p$ is energy price index, and $y$ is real GDP. The number in parenthesis is t-statistic. $p$ is the probability of accepting the null hypotheses that there is no serial correlation, no heteroskedasticity, and residuals are normally distributed. $* * *, * *$ and $*$ denote significance at the 1,5 and 10 percent level, respectively.

In the long run, a one percent increase in electricity consumption causes an increase in real GDP by 0.46 percent (Panel A of Table 4). This result indicates that electricity consumption is a crucial determinant of real GDP. Therefore, the estimated equation illustrates the contribution of electricity consumption to real GDP. The impact of price on real GDP is also positive. The short-run dynamics result from ECM estimate is illustrated in Panel B of Table 4. In the short run, the relationship between output growth and a change in electricity consumption is positive, but is not statistically significant. Furthermore, the estimated coefficient of lagged change in electricity consumption is positive and significant. Therefore, a change in electricity consumption does affect the growth rate in the short run. There is no impact of the subprime crisis in the short run. The estimated coefficient of the ECT is significantly negative and takes the absolute value of less than one. This indicates that any deviation from long-run equilibrium will be rapidly corrected. 
It should be noted that the preferred ECMs are chosen because they pass the four main diagnostic tests. The results of Granger causality test in the short run are reported in Table 5.

Table 5 Results of Granger causality tests in the short run

\begin{tabular}{lllll}
\hline $\begin{array}{l}\text { Dependent } \\
\text { variable }\end{array}$ & \multicolumn{2}{l}{ Short-run causality } & $\begin{array}{l}\text { Long-run } \\
\text { causality }\end{array}$ \\
\hline \multirow{3}{*}{$\Delta e c$} & $\Delta e c$ & $\Delta p$ & $\Delta y$ & ECT \\
\cline { 2 - 5 }$\Delta p$ & - & $7.497 * * *[+]$ & $20.624 * * *[+]$ & $7.422 * * *$ \\
& $(0.002)$ & $(0.000)$ & $(0.009)$ \\
$\Delta y$ & $0.358[+]$ & - & $1.764[+]$ & - \\
& $(0.701)$ & & $(0.182)$ & \\
& $17.967 * * *[+]$ & $4.300 * *[+]$ & - & 0.210 \\
& $(0.000)$ & $(0.014)$ & & $(0.650)$ \\
\hline
\end{tabular}

Note: The Wald F-statistic is reported with the probability of accepting the hull hypothesis. [+] indicates a positive causation. ${ }^{* * *}$ and $* *$ denote significance at the 1 and 5 percent level.

Using the Wald test, the results show that there is long-run unidirectional causality running from real GDP to electricity consumption because the coefficient of the ECT is significant at the 1 percent level. On the contrary, the coefficient of the ECT is not significant when $\Delta y$ is a dependent variable. Therefore, there is no long-run causation running from electricity consumption to real GDP. However, there is positive shortrun bidirectional causality between electricity consumption and real GDP in Thailand. The results from the present study differ from the findings of Asafu-Adjaye (2000) and Chen et al. (2007). Compared with the results from other economies, the results of the present study are consistent with the results found by Sami (2011), but contradictory to those of Ho and Siu (2007). Furthermore, the results also disprove the electricity neutrality hypothesis.

The findings in the present study give policy implications for the country, including some other emerging market economies. Since the economy is dependent on electricity consumption, measures that can improve electricity supply efficiency deem necessary. Investing more in electricity infrastructure and setting up measures for energy conservation will help in achieving the long-run growth target.

\section{Conclusion}

Previously, the evidence of electricity consumption-GDP relationship is widely documented in the literature. The recently developed technique for cointegration and causality tests are used by many researchers. However, the findings appear to be mixed. There can be unidirectional causality, i.e., electricity consumption Granger causes GDP or GDP Granger causes electricity consumption. Furthermore, there some previous studies that document bidirectional causality between the two variables.

This study re-analyzes the causality between electricity consumption and real GDP for Thailand during 2000Q1 and 2014Q2. The bounds test in a trivariate framework is employed. The causality tests are performed using ECMs to detect long-run causations between the two variables. The empirical results show the existence of 
long-run unidirectional causal relationship running from real GDP to electricity consumption. The long-run linkage is found from the significance of the ECT in the VAR model augmented with the ETC. In addition, there exist short-run bidirectional causations between the electricity consumption and real GDP. The limitation of the present study is that the availability of time series data of electricity consumption in a short time span, even though the long-run relationships are found

\section{References}

Asafu-Adjaye, J., (2000), "The Relationship between Energy Consumption, Energy Prices, and Economic Growth: Time Series Evidence from Asian Developing Countries," Energy Economics, 22, 615-625.

Chandran, V. G. R., Shama, S., Madhavan, K., (2010), "Electricity ConsumptionGrowth nexus: The Case of Malaysia," Energy Policy, 38, 606-612.

Chen, S. T., Kou, H. I., Chen, C.C., (2007), "The Relationship between GDP and Electricity Consumption in 10 Asian Countries," Energy Policy, 35, 2611-2621.

Faisal, A., Nirmalya, C., (2013), "Electricity Consumption-Economic Growth Nexus: An Aggregated and Disaggregated Causality Analysis in India and Pakistan," Journal of Policy Modeling, 35, 538-553.

Ghosh, S., (2002) "Electricity Consumption and Economic Growth in India," Energy Policy, 30, 125-129.

Glasure, Y. U., Lee, A. R., (1997), "Cointegration, Error-Correction, and the Relationship between GDP and Energy: The Case of South Korea and Singapore," Resource and Energy Economics, 20, 17-25.

Granger, C. W. J., (1988), "Causality, Cointegration, and Control," Journal of Economic Dynamics and Control, 12, 551-559.

Halkos, G. E., Tzeremes, N. G., (2014), "The Effect of Electricity Consumption from Renewable Sources on Countries' Economic Growth Levels: Evidence from Advanced, Emerging and Developing Economies," Renewable and Sustainable Energy Reviews, 39, 166-173.

Ho, C. Y., Siu, K. W., (2007), "A Dynamic Equilibrium of Electricity Consumption and GDP in Hong Kong: An Empirical Investigation,” Energy Policy, 35, 2507-2513.

Narayan, P. K., Smyth, R., (2009), "Multivariate Granger Causality between Electricity Consumption, Exports and GDP: Evidence from a Panel of Middle Eastern Countries," Energy Policy, 37, 299-236.

Oh, W., Lee, K., (2004), "Causal Relationship between Energy Consumption and GDP Revisited: The Case of Korea, 1970-1999," Energy Economics, 26, 51-59. 
Oteng-Abayie, E, Frimpong, J., (2006), "Bounds Testing Approach to Cointegration: An Examination of Foreign Direct Investment-Trade and Growth Relationship," American Journal of Applied Sciences, 3, 2079-2085.

Pesaran, M. H., Shin, Y., (1999), “An Autoregressive Distributed Lag Modeling Approach to Cointegration Analysis," Chapter 11 in Econometrics and Economic Theory in the $20^{\text {th }}$ Century: The Ragnar Frisch Centennial Symposium, Strom, S. (ed.) Cambridge University Press: Cambridge.

Pesaran, M. H., Shin, Y., Smith, R. J., (2001), "Bounds Testing Approaches to the Analysis of Level Relationships," Journal of Applied Econometrics, 16, 289-326.

Phillips, P. C. B., Perron, P., (1988), "Testing for a Unit Root in Time Series Regression," Biometrika, 75, 335-346.

Sami, J., (2011), "Multivariate Cointegration and Causality between Exports, Electricity Consumption and Real Income per Capita: Recent Evidence from Japan," International Journal of Energy Economics and Policy, 1, 59-68.

Yoo, S-H., (2005), "Electricity Consumption and Economic Growth: Evidence from Korea," Energy Policy, 33, 1637-1632. 